

\section{Conferencia para la ceremonia en la Universidad de Lisboa}

\section{Conference for a ceremony in the University of Lisbon}

\section{Gui Bonsiepe}

Reitor da Universidade de Lisboa, Doutor Cruz Serra

Autoridades

Miembros del cuerpo docente

Colaboradoras y colaboradores de la Universidade de Lisboa

Estudiantes

Señoras y Señores

Les presento una serie de reflexiones abiertas, levantando preguntas y dudas, sin tener siempre las respuestas. Por eso las caracterizo como reflexiones inacabadas, fragmentadas, en estado de elaboración.

Les pido disculpar mi portugués más que imperfecto en forma del portunhol. Pero me parece que para esta conferencia, además sin el uso de material visual de apoyo - tal vez insólito para un diseñador -, resulta más apropiado recurrir al portugués en vez de a otro idioma.

Ocasionalmente haré uso de datos de América Latina, pues allí también las economías y las sociedades han enfrentado - y enfrentan - situaciones de fragilidad y vulnerabilidad que se traduce en amplios sectores de la población en un clima de precarización y pérdida de confianza en el futuro, afectando particularmente a las jóvenes y los jóvenes. Por eso hay en lo que a la experiencia de la precariedad se refiere, ciertas similitudes entre países latinoamericanos y algunos países Europeos, entre ellos Portugal que ahora parece salir de la crisis y superarla sin feroces sacrificios.

Al ser considerado digno para recibir una distinción académica surge la pregunta: Como cumplir las exigencias ligadas a tal reconocimiento, por el cual me siento muy honrado y muy agradecido? Más aún estoy agradecido tomando en cuenta que he tenido solamente pocos contactos con Portugal y sus instituciones universitarias, que no han ido más allá de encuentros esporádicos. Cierto, publicaciones principales - entre otras en forma de una trilogía del diseño, escritas, producidas y divulgadas en Brasil - pueden haber llegado a Portugal, constituyendo así una red virtual. 
Considero esta distinción académica no solo como un reconocimiento de un trabajo personal, que - visto fríamente - suma más fracasos que sucesos, sino en un sentido más amplio. Pues como profesional, como docente o como autor, uno no actúa en forma aislada, sino siempre insertado en una red de personas que en mayor o menor grado colaboran y contribuyen al trabajo que uno está haciendo, es decir realizando un trabajo en equipo.

Por idiosincrasia personal mantengo una actitud de reserva frente a cualquier festejo del EGO, que pueda contribuir al peligro de ser elevado en forma de una estatua sobre un pedestal - una estatua que solamente sirve para invitar a las palomas para cubrir la cabeza con guano.

Mantengo también una actitud de desconfianza contra cualquier forma de 'guruismos, es decir contra el fenómeno de personas que se presentan como líderes nutriéndose de fuentes misteriosas de inspiración para asumir el rol de orientador o <líder - un concepto que me provoca profunda aversión. Más aconsejable me parece confiar en la razón crítica si es que uno quiere asumir la responsabilidad y correr el riesgo para dar consejos en tiempos confusos intrincados, caracterizados por un inminente - y lo digo sin querer exagerar - cambio civilizatorio.

Particularmente fructíferos han sido los lazos con profesionales de otras áreas, sobre todo de las ingenierías y de las ciencias y - no en menor grado - de empresarios que apostaron a la colaboración de una profesión vaga con un bajo grado de reconocimiento, a pesar del hecho de que hoy en día los términos «Design` $\mathrm{y}$ «Designer gozan de considerable popularidad, más aún con la propagación de una nueva panacea llamada «design thinking> que comentaré más adelante.

Poniendo los aspectos personales de lado me parece un síntoma muy alentador y al mismo tiempo revelador que para este título honorifico ha sido tomada en cuenta una actividad profesional y académica central de nuestra civilización técnico-científica de alta densidad material e informacional, es decir la actividad de Proyecto. Por tener un alcance más amplio prefiero usar el término 〈Proyecto〉 en vez del término «design` que por su popularización y elasticidad semántica ha perdido - y sigue perdiendo - precisión abriendo un espacio para interpretaciones simplicistas, reduccionistas, confusionistas, oportunistas y no diferenciadoras. La aparente atractividad de la palabra «design se basa en la propia indeterminación del significado de esta palabra.

Vine por primera vez a Portugal hace casi cuarenta años en 1979, con un encargo de la agencia de Naciones Unidas para el Desarrollo. Tenía que dar durante un mes un curso de diseño de muebles y productos de madera para un grupo de profesionales afines a esta temática y formar - en base de cortas visitas a algunas empresas - una idea, aunque provisoria, sobre el estado del diseño en las pequeñas industrias de muebles y de madera en el país después de la Revolución de los Claveles (1974). Además tenía que formular propuestas para mejorar el estándar de diseño industrial de las alrededor milcuatrocientos pequeñas empresas del sector de muebles y productos de madera que existían en aquel momento en Portugal. Obviamente este proyecto se encuadró en los preparativos de Portugal para su futura entrada siete años más tarde en el Mercado Común (1986) y para reducir el peligro de ser aplastado por la masa de productos diseñados y producidos con un mayor índice de productividad y precios competitivos.

Era una institución gubernamental que inició este proyecto, la Direção Geral da Qualidade, es decir una institución pública dedicada en primer lugar a la formulación de normas, evaluación, certificación, ensayos e información sobre materiales, y solo marginalmente a una actividad de innovación en forma de un proyecto. Debe-se reconocer la sensibilidad y visión de los ingenieros responsables para manejar la institución que abrían una puerta para la actividad proyectual. Raras veces en la historia del diseño se registra la importancia de estos profesionales. En general no se los menciona, tal vez por considerar el diseño como actividad perteneciendo más al área de las artes y no al dominio de la tecnología e industria, haciendo uso de la aureola misteriosa de la creatividad - un concepto enigmático muy apreciado como diferenciador para la profesión de los diseñadores, a veces no teniendo en cuenta que la creatividad no es una característica exclusiva o un monopolio de esta profesión.

En aquella época el término «diseño industrial` no fue usado en Portugal, probablemente debido a la particularidad del idioma portugués en el cual el término «desenho» no incluye 
una faceta proyectual, sino simplemente denota el resultado de la actividad de trazar una configuración sobre papel. En aquel momento yo no hablaba portunhol como ahora; por eso supongo que había dado el curso para los diecisiete participantes en español. En el informe final se usó la importación lingüística anglosajona «design industrial〉.

La oferta para venir a Portugal me llegó cuando estaba trabajando en un estudio de diseño junto con dos colegas - un arquitecto y un ingeniero - en Buenos Aires. Llegué a Portugal pasando por el desvío de América Latina. Después del cierre por motivos políticos de la hoy casi mítica Escuela de Ulm en 1968 me había mudado a América Latina, primero a Chile, mediante un contrato con la Oficina Internacional de Trabajo, y posteriormente a Argentina y a Brasil. Allí, en un contexto cultural, tecnológico, social y político diferente tuve que relativizar lo que había aprendido en el Centro y comenzar a levantar algunas dudas respecto a la pretensión de modelos universalmente válidos. En otras palabras: tuve que aprender de nuevo, sin caer en la tentación de una regresión romántica anti-industrial, anti-tecnológica y anti-moderna. Estuve consciente del peligro de asumir una postura paternalista - una trampa peligrosa - que debía evitarse. Pero mantuve sin cuestionamiento el término «desarrollo». Lo tomé como una realidad incuestionable. Hace cuarenta años atrás no me daba cuenta de las limitaciones del enfoque unidimensional y de la presuposición que el diseño en los países periféricos tenía seguir en rasgos generales al mismo esquema historicamente pre-establecido de supuesta validez universal - un concepto que el antropólogo Escobar propone substituir por el neologismo «multiversal».

Admito que desde el inicio tuve una postura reservada frente al enfoque que abogó - y aboga - por la búsqueda de una supuesta identidad latinoamericana del diseño en los raíces de la cultura precolombina. Es comprensible hacer valer la historia propia del parque de los productos artesanales pre-industriales de cada país. Pero la taxonomía del parque de productos del sector artesanal es bastante limitada y difícilmente puede satisfacer la demanda por productos diferenciados y complejos. Además, esencialismos y posturas hasta nacionalistas me parecían un camino errado para el diseño, sin menospreciar de ninguna manera la calidad de productos artesanales locales, como pude constatar más tarde especialmente en países como México, Colombia, Bolivia y Ecuador que disponen de una rica cultura artesanal. Pero me parecía y me parece - que el diseño industrial y de la comunicación deben buscarse y crearse en el futuro. Pues la identidad no es dada y fija, sino más bien creada y en flujo dinámico.

Mantuve una postura aprendida de mi mentor intelectual Tomás Maldonado, uno de los más grandes representantes del discurso del Proyecto en el siglo vente. Como joven artista e intelectual ya en los años 1940 consideró al mundo técnico-industrial de los artefactos y de los signos como nuevo desafío para crear una cultura humanista técnico-industrial basada en las ciencias. Continuar este enfoque en el contexto latinoamericano me parecía válido y prometedor, aunque la relación entre diseño y ciencia no ha sido - y no es - libre de conflictos y malentendidos. El lado fuerte de las ciencias es su disposición de argumentar sobre una base empírica, y no contentarse con una simple expresión de opiniones y vaguedades. Mientras inicialmente la enseñanza del diseño disfrutó unilateralmente del aporte de las ciencias, sobre todo de la matemática finita, de la teoría de sistemas, de la psicología de la percepción, hoy en día son las ciencias a las cuales el diseño puede aportar, por ejemplo mediante la visualización de información científica y el mapeamento de estructuras complejas contribuyendo a hacerlas más comprensibles, consolidando así el nuevo campo de acción llamado knowledge design, un área con contornos aún no claramente definidos. Desde el diseño de comunicación se puede entrar en el área cognitivo que es la característica del trabajo científico. Ahí se abre un enorme desafío para los diseñadores de comunicación excediendo las áreas tradicionales de trabajo del diseñador gráfico con las temáticas de publicidad, de marcas, del branding y del web design. Aceptar este desafío requiere una revisión de los planos de estudio de diseño dando espacio a un campo descuidado que es la textualidad complementando así la preocupación intrínseca de los diseñadoras y diseñadores por la visualidad. Esto no significa substituir el trabajo de diseño por el habla sobre el diseño, el trabajo de proyecto por el discurso de proyecto. Diseño no es - por más que representantes del postmodernismo puedan pretender - un texto.

En la medida en la cual comencé a adquirir experiencia con el trabajo en lo que hoy en día se llama Países Periféricos, 
incluyendo los países clasificados como emergentes, y en aquel tiempo se llamó Países en Desarrollo, creció mi interés por ver como estos países enfrentaban al proceso de modernización e industrialización y cual rol podía cumplir el diseño en este proceso - si es que podía cumplir un rol y no simplemente limitarse a unas intervenciones efímeras. En otras palabras, se trató - y se trata-de buscar una respuesta a una cuestión simple a formular, y no tan simple a responder: Como hacer del diseño una actividad socialmente relevante, pues la sociedad y lo social abarca aspectos que exceden el mercado visto bajo la estrecha perspectiva económica y financiera. En frente a la crisis ecológica agrego hoy la pregunta: Como hacer del diseño una actividad ecológicamente relevante?

La temática del desarrollo había entrado en el discurso público en el año 1949 en el marco de una conferencia del presidente de los USA, Harry Truman. Esta conferencia marcó el comienzo oficial de la Guerra Fría-hoy substituida por Guerras Tibias - , pues mediante el desarrollo se pretendía contrarrestar la posibilidad de que los países que habían ganado su independencia podían e iban a caer bajo la influencia de la órbita de la Unión Soviética o del campo de los países socialistas.

En aquel tiempo los términos «industrialización〉y «desarrollo〉 poseían en general connotaciones positivas aunque ya existían alertas sobre las innegables consecuencias ecológicas y sociales negativas del desarrollo. Pero a pesar de las alertas, la modernización en forma de la industrialización parecía ofrecer una llave para mejorar el estándar de vida de una sociedad. Por cierto, era reconfortante cultivar la idea que un trabajo profesional en el campo de diseño podía aportar algo para hacer este planeta un poco más habitable, contrarrestando las críticas simplistas contra el diseño industrial de ser nada más que una herramienta para fomentar la obsolescencia artificial, y contra la comunicación visual de ser nada más que un conjunto de técnicas seductoras para acelerar la circulación de mercadorías, estimulando un consumismo desenfrenado. La realidad es un poco más compleja que estas críticas simplistas condenatorias hacen suponer.

Pero, la imagen de la profesión no es libre de sombras. Para ilustrar esta afirmación cito un escritor alemán, un agudo observador de la realidad cultural y política, que en un párrafo demoledor en uno de sus textos de ficción recientes hace emitir a la figura principal un juicio sardónico casi liquidando el diseño industrial dejando nada para salvar esta actividad. Este escritor es considerado hoy uno de los mejores escritores y estilistas en Alemania, por eso cito este párrafo sin cometer el desliz de tratar de parafrasearlo: «Cuando el observó que uno de nosotros se había sentado en una silla plegable de plástico transparente color rosa, Z. (la figura principal no se identifica por un nombre, sino simplemente por la letra zeta) comenzó una tirada contra los diseñadores: «Desde que el último de los sucesores del Bauhaus había entregado su alma, esta gente se ocupa con hacer inutilizables todos los objetos de uso. Lo que ellos llaman creatividad, es una amenaza. A sus triunfos pertenecen la eliminación de la llave de agua, la construcción de repisas torcidas, el invento de lámparas, que no tienen la forma de lámparas y que dan en lo posible poca luz, y de oportunidades de sentarse, que no solamente bailan, sino que - como la famosa silla de Gerrit Rietveld - se burlan de la anatomía humana. La plusvalía de estos objetos consiste en ser decorados con el nombre de su autor.)[...] Debe imaginarse el infierno como un lugar completamente amoblado por diseñadores.» (Enzensberger, Hans Magnus. Herrn Zetts Betrachtungen. Berlin: Suhrkamp, 2013, S. 58.) [Reflexiones del Señor Zeta].

Cierto, se trata de un texto literario, pero esto de ninguna manera disminuye su veracidad. Pues la verdad no es monopolio de la ciencias. Textos literarios pueden dar y dan a veces con una formulación compacta y tajante en el clavo.

Un estudiante que lee el párrafo citado tal vez se quedaría desorientado, desanimado y se preguntaría si vale la pena estudiar una carrera con una imagen tan cuestionable. Cito el ejemplo no porque lo apruebo sin reservas, sino porque en buena medida es la propia profesión de los diseñadores que es responsable por este descrédito.

Para entender el papel del diseño en los países periféricos conviene echar una mirada al escenario internacional del comercio globalizado, sobre todo a partir del año 1989. Según una visión hegemónica corresponde a los países periféricos en primer lugar integrarse al comercio internacional como exportador de commodities, es decir en primer lugar como proveedor de materias primas crudas 
tales como petróleo, gas, hierro, cobre, aluminio, litio, soya, trigo, carne, maderas, café, cacao, azúcar, condimentos, algodón, y en el futuro posiblemente agua potable. Estos productos por su naturaleza no requieren diseño, son productos intrínsecamente asépticos al diseño, blindados contra intervenciones proyectuales.

Es exactamente en este punto en el cual surgen a la vista los aspectos políticos escondidos del diseño. Pues en este contexto el diseño periférico no se conforma con el rol del subordinado obediente. Puede ser visto como una aunque tenue expresión de disconformidad con un esquema hegemónico, cuyo poder se manifiesta en la transferencia asimétrica de valor. Esta afirmación se apoya en datos empíricos proporcionados en gran medida por la CEPAL (Comisión Económica para América Latina). A título ilustrativo selecciono Argentina y Brasil. Durante el período entre 1900 hasta 2010 los precios por unidad para importaciones crecieron de 50 hasta 596, es decir por doce veces, mientras los precios por unidad de las exportaciones crecieron solamente siete veces (de 50 a 366). Los valores para Brasil muestran una tendencia similar: los precios por unidad de las exportaciones crecieron 19 veces de 22 a 425 , mientras los precios por unidad de las importaciones crecieron 36 veces (de 25 a 899). Las causas por esta tijera que se abre no son solamente de carácter económico, pero de todos modos son reveladores. Revelan los efectos de la política del extractivismo y neo-extractivismo practicado también por gobiernos supuestamente populares, y porque los países periféricos a pesar de grandes reservas naturales no salen de la espiral del endeudamiento, que se revela como una nueva forma de dominación. Se registra estos fenómenos también en algunos países miembros del Mercado Común Europeo que se subordinan a las condiciones impuestas por instituciones financieras internacionales limitando el espacio de acción de los países endeudados, generalmente criticados por el exceso del gasto público. Esta crítica convence poco cuando se uno observa los operativos para salvar los bancos quebrados involucrados en especulaciones con títulos al futuro o créditos en el sector inmobiliario - los bad loans.

Ya en los años veinte del siglo pasado algunos países periféricos como Argentina habían comenzado con una política de desarrollo industrial propia, llamada posteriormente «política de substitución de importaciones»
- una tendencia que en los años 1960 fue reforzada e implementada en mayor o menor grado por todos los países de aquella región. Por ejemplo, en 1964 se creó en la Argentina uno de los cursos universitarios con gran influencia basado en el enfoque ulmiano. Similarmente en Brasil con le creación de la ESDI en Rio de Janeiro. También hubo editoras que publicaron traducciones y obras locales sobre la temática del diseño. Hubo un vivo discurso de diseño. En esta fase se expandió el diseño de tal grado que el diseño industrial y gráfico local bien podían medirse con el nivel de diseño de países centrales. Particular destaque merece el diseño de productos para el sector público - señalización urbana, equipamiento para escuelas en Argentina, y equipamiento para hospitales como era el caso de Brasil.

La política industrial era implementada con el fin de aliviar la balanza de pagos del comercio exterior, fomentar el desarrollo de la industria local, satisfacer la demanda del mercado interno y desarrollar productos apropiados para las condiciones locales para las cuales no se encontraban productos en el mercado externo.

Inevitablemente se tocan en este contexto cuestiones políticas, no en el sentido de partidos políticos sino relacionadas con el poder y la búsqueda de una manera para participar como actor en una sociedad futura en la cual uno gustaría vivir, es decir vivir como sujeto activo de la historia y no simplemente como un reflejo pasivo de la historia. En otras palabras, se toca aquí una cuestión central del diseño: la cuestión de la autonomía.

El diseño actual se encuadra en un marco general de crisis más amplia en esta fase histórica - como Badiou la llama: «capitalismo mundializado, implementado hoy a nivel mundial con rigor implacable. Menciona siete características:

- La financialización de la economía

- La crisis del concepto «desarrollo〉

- La transformación de bienes comunes en bienes privados

- El deterioro ambiental (la crisis climática, la contaminación)

- La creciente desigualdad

- La retracción de intereses sociales

- La crisis de la representatividad democrática. 
Vivimos hoy en el clímax de un programa preparado paciente - y sistemáticamente desde el comienzo de los años 1940, alcanzando prácticamente todo el planeta.

En el marco de los cambios mencionados se comenzó hablar de la «economía creativa que abarca ramas de actividad económica relevante que no habían sido tomadas en cuenta por los economistas que calculan el Producto Interno Bruto. En este campo llamado por falta de un mejor término industrias culturales han sido incluido los medios, consultorías, investigación y desarrollo, entretenimiento y arquitectura, publicidad y música, diseño y servicios de internet, exposiciones, moda y turismo.

Comenzó un creciente proceso de semiotización de los productos con un desplazamiento del interés tradicional por el uso y por la utilidad de un producto hacia los aspectos estéticos y de novedad, creando una nueva forma de valor: El valor estético o - más amplio - el «valor de escenificación`. Mientras en la economía clásica se habló del binomio valor de uso / valor de cambio, hoy el valor de uso por el cual el diseñador se preocupa está relegado al trasfondo, y se dirige a la apariencia. Este fenómeno ha sido caracterizado de la siguiente manera: «Por lo tanto la economía no constituye más un instrumento para la satisfacción de necesidades. Más bien es a la inversa: El hombre trasforma su sistema de necesidades, para responder a las exigencias del desarrollo capitalista, es decir un desarrollo cada vez más en forma de crecimiento.» (Böhme, Gernot. Ästhetischer Kapitalismus. Berlin: Suhrkamp Verlag, 2016)

Con la expansión y consolidación de la enseñanza del diseño, surgió y ganó terreno el tema de la teoría del diseño. La academización de la enseñanza llevó a un creciente número de publicaciones, resultado de los cursos de maestría y doctorado que en general requieren para el otorgamiento del título la entrega de un trabajo de investigación, en buena parte en forma de un texto. Por tres razones considero con cautela el uso del término «teoría de diseño».

Primero, por evocar la clásica división y hasta oposición entre teoría y práctica.
Segundo, por considerar bastante ambicioso hacer uso del término 〈teoría que en las ciencias se caracteriza por la disposición de basarse en juicios para los cuales se puede proporcionar evidencias y argumentos coherentes.

Tercero, por lo que se llama 〈complejo de cenicienta〉 («cinderella complex») (Isaiah Berlin).

La opinión que existe un zapato - la palabra teoría de diseño - para el cual en algún lugar debe haber un pié.

La aceptación del término «teoría de diseños puede también ser explicada como una saludable reacción a la tradicional debilidad discursiva de los diseñadores.

Me permito mencionar una anécdota personal: en 1970 trabajé en Chile en el marco de un proyecto multinacional. Los estudiantes que habían logrado el permiso de la universidad para trabajar con migo fuera de la universidad en proyectos concretos para la industria, un día me decían que tenía que conocer a un joven ingeniero - vice-rector de la Universidad Católica en Santiago. Lo invité a casa para tomar un té. Vino, intercambiamos algunas cortesías, y nos despedimos. Más tarde cuando nos habíamos hecho amigos el me confeso: Tenía una imagen muy mala de los diseñadores, pues como los arquitectos son confusionistas. Pero, me daba cuenta que debía corregir mi juicio, cuando detecté sobre una de las repisas de la biblioteca el libro de Stafford Beer Cibernetica y gestión. En aquel momento había dos personas en Chile que conocían este libro fundamental: El otro era Ud. Por esta casualidad se abrió el camino para poder participar como diseñador junto con un grupo de jóvenes diseñadores y diseñadoras chilenos recién egresados en el proyecto emblemático de la sala de operaciones del Proyecto Cybersyn, o centro de gestión de la economía chilena, posiblemente el proyecto más conocido internacionalmente de Chile. Cuento esto para hacer ver la importancia de la lectura. Había tenido la suerte, tener cursos de cibernética en la segunda mitad de los años cincuenta, cuando la teoría de sistemas y la cibernética se consolidaron como disciplinas fundamentales para comprender una variedad de fenómenos. En aquel momento no me daba cuenta de las implicaciones de haber tenido aulas sobre estas temáticas nuevas y podía leer libros recomendados por los docentes. Hubiera sido aberrante preguntarse en aquel 
tiempo, para qué estos cursos servían en una escuela de diseño. La importancia de estos cursos aparentemente inútiles se reveló décadas después. Cierto, era la lectura de libros, no una lectura limitándose a masivas mensajes online vía Facebook, Twitter, y whatsapp, es decir lo que se llama social media. Era otro tipo de lectura que requería y posibilitaba concentración y atención-difíciles a conseguir con los medios sociales con la atención parcelada a pequeños bocados.

Para consolidar el diseño como disciplina académicamente aceptada y aceptable debe expandirse la investigación de diseño (design research), tanto dentro como afuera del ambiente académico. Uno de los campos subinvestigados (underresearched) es la historia del diseño, fuertemente marcado por el enfoque de la historia del arte, aunque el aparato cognitivo de esta disciplina no es particularmente preparado para la historia del diseño, ya que opera preferentemente con cuestiones de forma y estilo. La historia del diseño debería ser desarrollada en un marco más amplio, en el marco de la historia de la civilización técnico-industrial de los artefactos materiales y simbólicos.

Desde hace algunos años se registra un fenómeno sorprendente: el uso inflacionario de la palabra «diseño 0 <design», atractivo por su vaguedad y polisemia. Es la propia indeterminación del concepto < design` que lo hace tan atractivo. La creciente atractividad de la palabra 〈design〉 se manifiesta a título ilustrativo en el uso del ampliamente divulgado término «design thinking». Si con este término se quiere referirse a la manera específica de los diseñadores para acercarse a un problema, no constituye ninguna novedad para los profesionales de diseño. Puede tal vez estimular el interés por desvelar el funcionamiento de esta supuesta capacidad específica. El peligro sin embargo consiste en hacer suponer o insinuar que un título en design thinking habilita para hacer diseño profesionalmente, hacer proyectos en forma concreta. Por eso no debe sorprenderse que por ejemplo un conocido científico del análisis de interfaces digitales y artefactos materiales cuestiona la legitimidad del uso de este concepto que para el es lo que se conoce por el viejo término «creatividad (Donald Norman). Supongamos que existe algo como medical thinking y certificados para medical thinking. Sin embargo un paciente consultará a un médico competente que cura, y no a un medical thinker que nunca en su vida ha curado un paciente.

Retomo la orientación del trabajo de diseño que se caracteriza por su orientación al futuro y una sensibilidad para detectar algo que falta en el presente y que puede ser mejorado en el futuro. El diseño ligado a la modernidad y a la modernización, puede manifestarse en dos vertientes: reformar la realidad o transformar la realidad. Ahí se toca nuevamente la faceta política de la actividad proyectual, entre un enfoque moderado y un enfoque potencialmente radical. Un enfoque que se queda en el marco de las reglas establecidas y un enfoque que se dirige a trascender las reglas vigentes. Ambos enfoques tienen sus riesgos: por un lado enfilarse en el conformismo y por otro lado perderse en un verbalismo radical sin consecuencias, limitado a comunicados y nada más que comunicados de exigencias programáticas.

Durante años no era nada excepcional relacionar diseño y utopía, pues ambos se refieren a la dimensión del futuro. Pero hoy el término <utopía ha sido relegado al trasfondo del debate. Se registra hasta un desgaste del término y un cansancio causado por el imperativo utópico lo que revela el espíritu de la época. Lejos se está de los años sesenta y el sesentayochismo y más afín al pensamiento distópico o peor al cinismo - actitud que no me parece defendible.

Uno de los aspectos del cambio civilizatorio que había mencionado anteriormente se refiere a la revisión del concepto y del tipo de «desarrollo que lleva al consumismo, ya que hoy se trata de superar un modelo de crecimiento basado en la explotación de fósiles, sobre todo petróleo y carbón. No solamente significa cambiar la matriz energética de una economía, sino revisar el estilo de vida orientándose a otros valores, más solidaridad y empatía, y menos competencia y agresión, reduciendo el enorme desequilibrio en el uso de recursos del planeta - reflejo del alto porcentaje de pobreza que agobia la mayoría de los países periféricos. Algunos abogan por un cambio radical frente a la natura, no considerándola más simple - y predominantemente como un «recurso a ser explotado, sino desde una perspectiva incluyente. Obviamente se toca aquí temáticas profundas de la cultura occidental que se extienden hasta cuestiones de la religión judeo-cristiana. 
No se trata más de un desarrollo sino de un post-desarrollo cuyas características y contornos aún están difusas y que quedan por definir con más precisión.

Admito mi perplejidad frente a la pregunta: Cómo inventar un programa de estudio para las profesiones de diseño en el marco del post-desarrollo. Pues no se trata simplemente de un crecimiento sustentable que queda todavía en el marco conceptual tradicional del desarrollo, sino de dejar detrás el concepto de desarrollo industrial.

Como es sabido la carrera del diseño en general goza de una considerable atractividad. Tanto es así que hubo una explosión de todo tipo de cursos en los cuales figura la palabra «diseño» sobre todo a partir de los años noventa. Pero, esta atractividad contrasta con una realidad preocupante; por ejemplo en Chile hay alrededor 150 cursos de diseño, pero en el ranking de empleabilidad la carrera de diseño figura en el último lugar. Parece que entre las pocas posibilidades de empleo se encuentra la industria de la educación misma, reintegrando egresados como docentes que posiblemente nunca han ejercido la profesión en el ámbito extra-académico. Dejo abierto si esto es un fenómeno saludable o más bien preocupante.

Este fenómeno forma parte del problema general del desempleo. Se pronostican escenarios alarmantes de probable desempleo tecnológico masivo entre otros causado por la conexión en red de artefactos, llamados objetos inteligentes. Dejo de lado si se justifica usar el término «inteligente> para este tipo de artefactos. Por ejemplo, con la expansión de automóviles autónomos pasará a los taxistas lo que pasó a los cocheros, hoy una profesión extinguida. Particularmente amenazadas son actividades que se basan en la ejecución de rutinas. Se estima que $90 \%$ de los casos jurídicos en los USA pueden ser resueltos mediante programas digitales. Esto afectará al empleo de los abogados. Hasta el momento la actividad de diseño se encuentra relativamente protegida, pues se caracteriza - como la invención - por basarse en procesos que se escapan de la algoritmación. Tal vez las investigaciones en el campo de las neurociencias ayudarán a comprender el proceso de diseño que hasta el momento es una caja negra.
Con este tour d'horizon espero haber podido esbozar la amplitud del diseño, con tantas ramificaciones que tocan a los puntos neurálgicos de nuestra civilización. De ninguna manera quise desanimar a los estudiantes de la carrera diseño, una carrera con aspectos críticos, y hasta muy críticos, pero no por eso desdeñable. Me permito una conclusión con una dosis de aliento: el diseño vale, y vale y vale. Renunciar al futuro es optar por la práctica del no-diseño. Esto nunca debería ser una opción para una diseñadora o diseñador. Nunca. Lo que vale es el imperativo proyectual.

\section{Pronunciamento proferido por ocasião do recebimento do título Doutor Honoris Causa junto à Universidade de Lisboa, Portugal, em 20 de março 2018.}

Gui Bonsiepe é designer, educador, pesquisador e autor de obras na área de design, publicadasna Alemanha, Argentina, Brasil, Coreia, Espanha, Holanda, Itália, México, Portugal e Suíça. Graduado na Alemanha, foi docente e pesquisador na HfG Ulm, consultor e freelance para organismos internacionais, instituições públicas e empresas privadas na América Latina. Coordenou o Laboratório Brasileiro de Design Industrial em Florianópolis e o programa de mestrado em design de informação na Universidade das Américas em Puebla (México). Foi professor de interface design na Universidade de Ciências Aplicadas, em Köln (Alemanha). Possui cinco títulos Doutor Honoris Causa, concedidos por universidades do Brasil, Argentina, México, Chile e Portugal.

Nota: texto autorizado pelo autor para publicação na Revista Pensamentos em Design, por solicitação do Dijon De Moraes, membro do Conselho Editorial. 